\title{
Implementation of Apriori Data Mining Algorithm on Medical Device
}

\section{Inventory System}

\author{
Meidar Hadi Avizenna ${ }^{1, *}$, R Arri Widyanto ${ }^{2}$, Dwi Kusuma Wirawan ${ }^{3}$, Teguh Adhi Pratama ${ }^{4}$, Amandha shafa Nabila $^{5}$ \\ Department of Information Technology, Faculty of Engineering, Universitas Muhammadiyah Magelang, Indonesia \\ meidar@unimma.ac.id ${ }^{1, *}$; arri_w@ummgl.ac.id ${ }^{2}$; dwikus1234@gmail.com ${ }^{3}$; hugetadhi894@gmail.com ${ }^{4}$; \\ amandanabilla763@gmail.com 5 \\ * corresponding author
}

(Received July 5, 2021 Revised August 9, 2021 Accepted August 28, 2021, Available online September 29, 2021)

\begin{abstract}
The pattern of the need for drugs and medical devices in various hospitals has a tendency to be repeated and similar in a relatively long period of time, especially in one particular department, because the cases found are often similar or even similar. Ensuring the availability of stock in each departmental depot is very vital, because the procurement of medical devices must go through a certain process and time, so that cases of critical rheumatism often occur but the equipment needed at depositors does not meet the standards. need or run from inventory and must indent first. By calculating the trend of demand patterns and needs using an algorithm (Apriori Association) in the dataset, a rule is formed that in the pattern of dependence between itemsets that have supporting criteria in the form of 33.3\% support and $85 \%$ Confidence, where the items that appear are items with frequency of occurrence and associations so that it can be taken into consideration to ensure the availability of drugs and medical devices.
\end{abstract}

Keywords: Data Mining, Association Rules, Apriori Algorithm, Medical tools

\section{Introduction}

With the advent of advanced medical technology and drugs, spending on health care delivery has increased disproportionately in comparison to available resources. One of the most vital facilities for patients is the storage section which collects data on all products and equipment in the hospital. In its activities, the storage department does not only carry out medical activities with machines but also requires medicines and other medical devices.

In the procurement process, the storage department checks the department's savings, then looks at the functional level with the remaining stock with the level of needs and cases that are often found [1]. Then the officer asked for the goods that must be restocked, to be forwarded to the pharmacy warehouse. Due to the increasing number of medical activities, especially in the area where researchers conduct research, several problems were found. One of the problems found was the lack of need for drugs and medical devices available in warehouses and pharmacy warehouses, delays in the distribution of goods, and vacancies in stock [2]. While the frequency of indent items is always routine so that related items and items that appear have a high level and tendency of similarity between items by looking at the history of previous indent transactions.

The absence of a standard method used in dealing with drug supply problems often creates problems, especially when large quantities of certain drugs are needed [3]. This is because the purchase of drugs to meet drug supplies in pharmacies is only based on drug data that will run out. The application of data mining algorithms can assist in analyzing drug inventory data so as to produce information that can be used in planning drug supplies in clinics and hospitals.

Planning for drug needs will affect the procurement, distribution, and use of drugs in health care facilities. Availability of types and quantities of drugs that are needed quickly enough by agencies that provide health services is very important. The provision of medical devices in very large quantities can pose many risks, such as the large costs incurred to store medical devices and are also prone to the risk of theft. Availability of medical devices can affect the quality of health services used [4]. Data mining using algorithms can be used to determine the associative relationship of item combinations by using support and confidence calculations from an itemset. A priori algorithm to 
analyze and determine the purchase of medical devices Data mining using a priori algorithm can be used in the health sector to determine the pattern of purchasing drugs and medical devices.

Data mining can be used to manipulate data into more valuable information obtained by extracting and recognizing important patterns from the data contained in a database. This study aims to find trends between one item and another, where the stronger the trend that appears will be used as a reference in the hospital policy process in ensuring the availability of these items when needed so that the procurement process can always be fulfilled.

\section{Literature Review}

An inventory is a detailed itemized list of assets held by an organization or institution. To be worthwhile, an inventory must be continually maintained and updated to reflect the current status of each asset. Depending on the nature of the organization and its associated assets, different details are tracked and updated as changes occur [5]. The goal is to have an accurate, up-to-date record of all assets held by the organization, reflecting the current status at any given moment in time. Within the scope of HTM, an inventory is the first and most important tool for achieving several broad aims:

- A medical equipment inventory provides a technical assessment of the technology on hand, giving details of the type and quantity of equipment and the current operating status.

- The inventory provides the basis for effective asset management, including facilitating scheduling of preventive maintenance and tracking of maintenance, repairs, alerts and recalls.

- The inventory can provide financial information to support economic and budget assessments.

- The inventory is the foundation needed to organize an effective HTM department. Items such as equipment history files and log books, operating and service manuals, testing and quality assurance procedures and indicators are created, managed and maintained under the umbrella of the equipment inventory. Furthermore, accessories, consumables and spare parts inventories are directly correlated with the main medical equipment inventory.

Inventories of medical equipment may be maintained at different levels within a country's health-care structure. At the national level, the ministry of health or other overseeing body may keep an inventory of highly sophisticated or regulated equipment, such as devices used in nuclear medicine and devices that emit ionizing radiation [6]. Such inventories may be used to ensure that the proper service is implemented to protect large investments of highly technical equipment and to monitor potential hazards, including radioactive and nuclear exposure. In cases where the state owns the assets, a national or regional/provincial inventory may be implemented [7].

Most medical equipment inventories, however, are held at the health-care facility level. For smaller organizations, such as a local clinic, the inventory may consist of a few simple items and may be updated very infrequently, if ever. Meanwhile, high-level specialized hospitals may have thousands of items listed in the inventory, with continual updates. Every inventory is unique to refl ect the facility's assets; the size and complexity of the inventory will depend on its type and purpose and the scale of the operation [8].

Many types of medical equipment require consumables and accessories. Therefore, in conjunction with the medical equipment inventory, the healthcare facility should maintain a separate inventory of consumables necessary to operate medical equipment [9]. These include items such as blood tubing sets, electrodes, electrocardiographic (ECG) paper, conductive gel and reagents. The inventory includes a stock-control system to track details such as quantities and expiration dates so that items remain in stock and are used before they expire [10]. Effective stock control of consumables inventory prevents stock-outs and allows budget estimates to cover the cost of consumables.

An equipment spare parts inventory is another important record that must be maintained in order to ensure safe and effective function of medical equipment [11]. For each medical device, it is important to have a stock of the items that wear over time or need to be replaced regularly, including filters, O-rings and other parts recommended by the manufacturer. In addition, general maintenance materials, such as fuses, screws and electrical wires, must be kept in supply through the use of the inventory. A spare parts inventory can assist in estimating the annual maintenance costs of the medical equipment stock.

Other inventories that could be implemented in support of or related to health-care technology include the following:

- Workshop tools and test equipment inventory: Assists the medical equipment maintenance team in keeping tools and test equipment organized, in good working order and in calibration.

- Industrial and hospital equipment: Items such as boilers, autoclaves, laundry equipment, generators, 12 Introduction to medical equipment inventory management and compressed air, vacuum and medical gas 
distribution systems, are all necessary to keep the hospital running smoothly and require maintenance. An inventory of such equipment is useful in managing the maintenance of this equipment.

- Safety equipment: Keeping an inventory of items such as fire extinguishers, fire hoses, alarms and eyewashes, and performing routine checks to ensure they are in good order, will ensure that they are functional when needed.

- Radioactive and hazardous materials and waste: Maintaining an inventory of such materials helps to ensure proper regulation and disposal and prevent unnecessary contamination.

The focus of this document is on medical equipment, consumables, spare parts, workshop tools and test equipment inventories. Discussions of inventories for industrial and hospital equipment, safety equipment, and radioactive and hazardous materials and waste are outside the scope of this document.

The main health-care technology asset to be included in an inventory is medical equipment. Such an inventory often remains separate from the main hospital asset inventory, since different information is needed for the purpose of HTM. The responsible department within the healthcare facility (such as a medical equipment maintenance department or clinical engineering department) determines which equipment should be included in the inventory. Some organizations choose to include all medical devices in an inventory, including small items such as stethoscopes and thermometers; for larger organizations, however, this may not be practical.

When an organization decides to eliminate some items from the inventory, it establishes a set of criteria by which to include or exclude each item. One method is to implement a risk-based inventory that identifies higher-risk equipment to be included in the inventory and medical equipment management plan, and lower-risk items that may safely be eliminated. The Association for the Advancement of Medical Instrumentation (AAMI), in its widely recognized standard Recommended practice for a medical equipment management program, requires that inventory inclusion criteria take into account the function of the equipment, the physical risks associated with the equipment, the maintenance requirements of the equipment and the incident history of the equipment. Fennigkoh and Smith [12] created a numerical algorithm to evaluate medical equipment based on equipment function, risk and required maintenance. This algorithm serves as a foundation for many inventory inclusion analyses in healthcare facilities worldwide. The algorithm is explained in Appendix A. An adaptation of this algorithm is found in Medical equipment maintenance programme overview in this technical series [13]. This adaptation adds the equipment incident history as a consideration, such that equipment with a higher frequency of failures moves up on the risk scale (and thus is more likely to be included in the inventory) and those with a lower frequency of failures moves down on the scale (less likely to be included in the inventory).

Building on specific model and the idea of a numerical algorithm to determine equipment inclusion in an inventory, many improvements and suggestions have been made to determine how to decide which equipment should be included in an inventory. Wang and Levenson [14] emphasized that the consideration of mission criticality and utilization rates is essential when deciding which equipment should be included in an inventory. Mission criticality identifi es how important the equipment is to the overall goal of the hospital. Equipment that is more important to the main mission of the hospital (for example, a piece of laboratory equipment used to perform routine tests) may be more important than high-risk or sophisticated equipment (such as a ventilator) of which there are many units available [15]. Furthermore, utilization rates consider how often a piece of equipment is used. For example, a piece of equipment that is used often and of which there is only one unit has a much higher utilization rate (and thus may be much more important) than a piece of equipment that is used rarely or of which there are several units (for example, defibrillators).

Wang et al. [16] discuss further different strategies for determining equipment to be included in an inventory and within a medical equipment management programme. Every healthcare facility has different equipment needs and usage rates, and the department responsible for medical equipment inventory should take all of these factors into consideration when determining which equipment should and should not be included [17]. Regardless of the method used to determine inventory equipment inclusion, it is important that the responsible department reassesses inventory equipment inclusion often, particularly when mission criticality or utilization rates change.

\section{Research Methodology}

To measure the level of need for drugs and medical devices that will be carried out to find the level of tendency between itemset using a priori algorithm, there are several steps that are carried out, namely:

\subsection{Data Source Analysis}

\section{1). Mount of Deposit Stock}


The main factor in the procurement of drugs and medical devices in the radiology department is to look at the amount of available stock deposited [18]. If it is estimated to be sufficient for several indent periods and rare cases, the indenting process will be carried out in the next indent period.

2). Indent Order Periods

The order period is the scheduled time to procure goods. The researcher uses the time limit of goods orders on routine procurement transactions and some random transactions.

\section{3). Departement Destination}

There are two departments that aim to supply drugs and medical devices, namely main store pharmacy and inpatient pharmacy. Because the main store pharmacy tends to have very few items, the researchers used data from the procurement of drugs and medical devices at the pharmaceutical department alone and ignored transactions in the main store pharmacy department.

4). Case Rate Against Drug Needs

The author uses and sets the assumption that items that frequently and tend to appear routinely indent transactions as items that are often used where in many cases the use of drugs and medical devices tend to be the same.

\subsection{Data Processing Process}

In the process of processing data in this study, as mentioned above, this research uses the A Priori Algorithm method in finding data processing. The steps taken are as follows:

\section{1). The process of counting Candidates}

The first step taken is to tabulate and define the itemset that arises from the entire transaction, with the aim to facilitate the calculation and determine the total overall appearance of the item against the total number of transactions that exist within a certain period.

\section{2). Process of Calculating Support Candidates}

After tabulation data has been made, then the templates that appear have been identified and the total number of transactions that have taken the next step is to carry out the calculation and determination of minimum 1-itemset and 2 -itemset support. is calculated using the formula that has been determined as follows. To calculate the 1-itemset support value the formula used is:

$$
\text { Support (A) }=\frac{\Sigma \text { Transaction Contain } A}{\Sigma \text { Transaction }} X_{100 \%}
$$

After getting a profit of each value from 1-itemset, the determination of the support value can be done, henceforth the items selected from the minimum support are then used as candidates for calculating the 2 -itemset value. Whereas to calculate the 2-itemset support value the formula used is:

$$
\text { Support }(\mathrm{A}, \mathrm{B})=\frac{\Sigma \text { Transaction Contain } A \text { and } B}{\Sigma \text { Transaction }} X_{1}
$$

Next, after getting the results of each frequency value, and the minimum support value has been determined, then the association rules are made.

\subsection{Creating Association Rules}

Based on the support value that has met the criteria, and the combination of the itemset that meets the minimum standard, then the confidence value will be calculated, i.e. the strength of the item in the total transaction containing the item.To calculate the confidence value of an itemset combination, use the following formula:

$$
\text { Support }(\mathrm{B} \mid \mathrm{A})=\frac{\Sigma \text { Transaction Contain } A \text { and } B}{\Sigma \text { Transaction Contain } A} X_{1}
$$

By finding the value of confidence it will be matched with the minimum support value of a predetermined combination of items, where both the value of support and confidence have a minimum value for each parameter 
specified. After the combination pattern is found, it is made as a conclusion from the calculation of the association rules and as an item that has the strongest support and confidence criteria.

\section{Result and Discussion}

In the process of processing data mining so as to produce a conclusion in the form of information, the stages that have been tested in the process are needed, then based on that the writer will use the following methods and stages:

\subsection{Data Analysis}

In this study, researchers used the results of indent order transactions from the storage department to the inpatient pharmaceutical department. Whereby following the applicable indent period, then in normal time that is twice weekly indent orders and the number of normal transactions in a year reaches 100 transactions. In this study, researchers took a span of three years (2019-2021), with 250 transaction data to be processed and then used as a useful source of information for both the storage department and the pharmaceutical department.

\subsection{Formation of Candidates and Itemset Frequency}

The types of items contained in all drug and medical device indentation transactions along with the number of occurrences of each itemset from the total number of indent order transactions that occurred during that period will be used as research benchmarks.

1). Formation of the Set-Item Frequency list

The first thing to do is to make a frequency list based on the indent order data that has been obtained.

Table. 1. Example List of Itemset Frequencies

\begin{tabular}{|l|l|l|}
\hline \multicolumn{1}{|c|}{ No Item Name } & \multicolumn{1}{c|}{ Transaction Mount } \\
\hline 1 & Alcohol Had & $61 / 250$ \\
\hline 2 & Alcohol Swab & $70 / 250$ \\
\hline 3 & Blue Sensor & $57 / 250$ \\
\hline 4 & White Apron & $1 / 250$ \\
\hline 5 & 3 Waystopcock Tails & $90 / 250$ \\
\hline 6 & Aquapack & $8 / 250$ \\
\hline 7 & Aquasonic Gel & $55 / 250$ \\
\hline 8 & Coil Connecting Tube & $81 / 250$ \\
\hline 9 & Betadine SOL & $37 / 250$ \\
\hline 10 & Buscopan & $15 / 250$ \\
\hline 11 & Dexamethasone & $7 / 250$ \\
\hline 12 & Diphenhydramine & $16 / 250$ \\
\hline 13 & Disposable Catheter TIP & $48 / 250$ \\
\hline 14 & Disposable Syringe & $122 / 250$ \\
\hline 15 & Disp Electrode & \\
\hline
\end{tabular}


After knowing each itemset that appears in the transaction along with the frequency of the item's appearance from existing transactions, then it will then enter the stage in the calculation process to find a value that meets the minimum support criteria to the stages of forming the association pattern.

\section{2). Formation of a 1-Itemset list}

In the process of forming 1 itemset, a minimum support value has been set at $33.3 \%$. This minimum value is considered as an indicator that is sufficient to reduce transactions where if under $33.3 \%$ an item is considered less influential on indent order transactions. The following are examples of calculation of 1-itemset formation:

$$
\begin{aligned}
3 \text { Waystockcock } & =\frac{\Sigma \text { Transaction Contain } 3 \text { Ways }}{\Sigma \text { Transaction }} X_{100 \%} \\
& =\frac{90}{250} \times 100 \%=36 \%
\end{aligned}
$$

Then with a determined value of support of $33.3 \%, 1$-itemset data can be determined that meets the minimum support criteria as shown in table 2 below:

Table. 2. List of 1-itemset that meets the Minimum Support Value of 33.3\%

\begin{tabular}{|l|l|c|c|}
\hline No & \multicolumn{1}{|c|}{ Item Name } & Transaction Mount & Support (\%) \\
\hline 1 & 3 Waystopcock Tails & 90 & 36 \\
\hline 2 & Disp Syringe & 122 & 48.8 \\
\hline 3 & Gadoterate Meglumine & 106 & 42.4 \\
\hline 4 & Lohexol 350 & 95 & 38.0 \\
\hline 5 & Lopamidol & 96 & 38.4 \\
\hline 6 & Metacosfar & 83 & 33.3 \\
\hline 7 & NaCL 0.9\% & 107 & 42.8 \\
\hline 8 & Sens Glove & 85 & 34 \\
\hline 9 & Tegaderm & 87 & 34.8 \\
\hline 10 & USG Paper & 92 & 36.8 \\
\hline 11 & Vasofix & 88 & 35.2 \\
\hline
\end{tabular}

\section{3). Formation of a 2-Itemset list}

The next step is the formation of a combination of 2 itemset patterns. The formation of a frequency pattern of two (2) items is formed from items of the type of medical devices that meet minimum support by combining all items into two combinations, the result of a combination of all types of items. The combination of each item that has been selected will be calculated to determine the combination that meets the $33.3 \%$ minimum standard of support in transactions that occur. The following is an example of a 2 -itemset formation calculation:

$$
\begin{aligned}
\operatorname{Support}(\mathrm{A}, \mathrm{B})=\mathrm{P}(\mathrm{A} \cap \mathrm{B}) & =\frac{\Sigma \text { Transaction Contain Sensi Glove and Lohexol } 350}{\Sigma \text { Transaction }} X_{100 \%} \\
& =\frac{53}{250} \times 100 \%=21.2 \%
\end{aligned}
$$

Then, with a determined support value of $33.3 \%$, 2-itemset data can be determined that meets the minimum support criteria as shown in the following table 3: 
Table. 3. List of 2-itemset that meets the minimum support value of $33.3 \%$

\begin{tabular}{|l|l|c|c|}
\hline \multicolumn{1}{|c|}{ No } & \multicolumn{1}{|c|}{ Item Name } & Transaction Mount & Support (\%) \\
\hline 1 & $\begin{array}{l}\text { 3 Waystopcock Tails \& Disposable } \\
\text { Syringe }\end{array}$ & 83 & 33.3 \\
\hline 2 & Disposable Syringe \& NaCL 0.9\% & 91 & 36.4 \\
\hline 3 & Disposable Syringe \& Vasofix & 85 & 34 \\
\hline
\end{tabular}

The above data is a combination of two selected data item patterns with predetermined support criteria where the combination of patterns meets the minimum support of 33.3\%. The combination data of Waystopcock Buntut with Disposable Syringe, Disp Syringe with $0.9 \% \mathrm{NaCl}$, and Disposable Syringe with Vasofix are itemset that meets the minimum support criteria. These results explain that the combination of the two data items is the most in a transaction.

\subsection{Formation of Association Rules}

By making item-A as Antecedent and Item B as Consequent, the association rules A $\rightarrow$ B are applied to be able to calculate the confidence value by determining a minimum confidence value of $85 \%$. Itemset candidates who have met the support value are items that will be a candidate for a combination of values from confidence. The following is an example of calculating the confidence value:

$$
\begin{gathered}
\text { Confidence }=\mathrm{P}(\mathrm{A} \cap \mathrm{B}): \frac{\Sigma \text { Transaction Contain } 3 \text { Ways and Disp Syringe }}{\Sigma \text { Transaction Contain } 3 \text { Ways }} X_{100 \%} \\
=\frac{83}{90} \times 100 \%=92.2 \%
\end{gathered}
$$

After getting the results of each confidence value based on the items of the combination that meet the support, then by applying the association rules where the value of support and confidence of each combination of items has met or above the minimum value that has been determined, then the combination that meets these criteria can be seen in the following table 4:

Table. 4. Formation of Association

\begin{tabular}{|l|l|c|c|}
\hline \multicolumn{1}{|c|}{ No } & \multicolumn{1}{|c|}{ Item Name } & Confidence (\%) & Support (\%) \\
\hline 1 & $\begin{array}{l}\text { 3 Waystopcock Tails \& Disposable } \\
\text { Syringe }\end{array}$ & 92.2 & 33.3 \\
\hline 2 & Disposable Syringe \& NaCL 0.9\% & 36.4 & 36.4 \\
\hline 3 & Disposable Syringe \& Vasofix & 34 & 34 \\
\hline
\end{tabular}

Based on the data in table 4, we get the association rules that meet the criteria of support and confidence with a minimum support value of $33.3 \%$ and a confidence value of at least $85 \%$, so it can be concluded that the three rules have a frequency and a strong interrelation between itemset.

\section{Conclusion and Suggestion}

This study is intended to look for combination patterns and items that most often appear as candidate items that will be used as references in each department to maintain the availability of drugs and medical devices, assuming the items resulting from the association pattern are the most frequent. required for patient action.

The method used to calculate frequency patterns and combinations is to use the Priori A Data Mining Algorithm technique as a data processing method and use a test from manual calculations to calculations with applications. After performing various calculation patterns, both through support and confidence, a combination of rules that meet these two parameters was obtained, namely the combination of 3 Waystopcock Tail and Disp Syringe with a support value 
of $33.3 \%$ and a confidence value of $92.2 \%$, a combination of NaCL $0.9 \%$ and Disp Syringe with a support value. $36.4 \%$ and a confidence value of $85.0 \%$, as well as the combination of Vasofix and Disp Syringe with a support value of $34.0 \%$ and a confidence value of $96.5 \%$ as a combination that meets the minimum parameters that are determined. By looking for a combination of these patterns, and the frequency of dominant items in the last transaction period, it is expected that both the storage department as a department in need can safely control inventory in departmental deposits, and the pharmacy department as a provider to ensure the availability of these items and ease of distribution. For further research, it can be carried out with updated data for current research needs, as well as using several different methods to prove the validity of existing research results.

\section{References}

[1] O. Agboola et al., "A review on the impact of mining operation: Monitoring, assessment and management," Results Eng., vol. 8, no. October, p. 100181, 2020, doi: 10.1016/j.rineng.2020.100181.

[2] P. K. Mishra, M. Bolic, M. C. E. Yagoub, and R. F. Stewart, "RFID technology for tracking and tracing explosives and detonators in mining services applications," J. Appl. Geophys., vol. 76, pp. 33-43, 2012, doi: 10.1016/j.jappgeo.2011.10.004.

[3] S. Xu and H. K. Chan, "Forecasting medical device demand with online search queries: A big data and machine learning approach," Procedia Manuf., vol. 39, no. 2019, pp. 32-39, 2019, doi: 10.1016/j.promfg.2020.01.225.

[4] A. M. Cruz, "Evaluating record history of medical devices using association discovery and clustering techniques,” Expert Syst. Appl., vol. 40, no. 13, pp. 5292-5305, 2013, doi: 10.1016/j.eswa.2013.03.034.

[5] J. H. Gruenhagen, R. Parker, and S. Cox, "Technology diffusion and firm agency from a technological innovation systems perspective: A case study of fatigue monitoring in the mining industry," J. Eng. Technol. Manag. - JET-M, vol. 62, no. August, p. 101655, 2021, doi: 10.1016/j.jengtecman.2021.101655.

[6] L. Li, "Real time auxiliary data mining method for wireless communication mechanism optimization based on Internet of things system," Comput. Commun., vol. 160, no. June, pp. 333-341, 2020, doi: 10.1016/j.comcom.2020.06.021.

[7] P. T. Bich Thao, S. Pimonsree, K. Suppoung, S. Bonnet, A. Junpen, and S. Garivait, "Development of an anthropogenic atmospheric mercury emissions inventory in Thailand in 2018," Atmos. Pollut. Res., vol. 12, no. 9, p. 101170, 2021, doi: 10.1016/j.apr.2021.101170.

[8] M. A. Sayed, X. Qin, R. J. Kate, D. M. Anisuzzaman, and Z. Yu, "Identification and analysis of misclassified work-zone crashes using text mining techniques," Accid. Anal. Prev., vol. 159, no. August 2020, p. 106211, 2021, doi: 10.1016/j.aap.2021.106211.

[9] T. wahyuningsih, "Text Mining an Automatic Short Answer Grading (ASAG), Comparison of Three Methods of Cosine Similarity, Jaccard Similarity and Dice's Coefficient,” J. Appl. Data Sci., vol. 2, no. 2, pp. 45-54, 2021, doi: $10.47738 /$ jads.v2i2.31.

[10] Y. N. Chi, "Modeling and Forecasting Long-Term Records of Mean Sea Level at Grand Isle, Louisiana: SARIMA, NARNN, and Mixed SARIMA-NARNN Models," J. Appl. Data Sci., vol. 2, no. 2, pp. 1-13, 2021, doi: $10.47738 /$ jads.v2i2.27.

[11] S. Shadroo and A. M. Rahmani, "Systematic survey of big data and data mining in internet of things," Comput. Networks, vol. 139, pp. 19-47, 2018, doi: 10.1016/j.comnet.2018.04.001.

[12] M. A. F. Ros-Tonen, J. J. Aggrey, D. P. Somuah, and M. Derkyi, "Human insecurities in gold mining: A systematic review of evidence from Ghana," Extr. Ind. Soc., no. April, p. 100951, 2021, doi: 10.1016/j.exis.2021.100951.

[13] M. Sharma, S. Joshi, and K. Govindan, "Issues and solutions of electronic waste urban mining for circular economy transition: An Indian context," J. Environ. Manage., vol. 290, no. October 2020, p. 112373, 2021, doi: 10.1016/j.jenvman.2021.112373.

[14] P. Zerbino, A. Stefanini, and D. Aloini, "Process science in action: A literature review on process mining in business management," Technol. Forecast. Soc. Change, vol. 172, no. July, p. 121021, 2021, doi: 10.1016/j.techfore. 2021.121021.

[15] N. Martin et al., "Recommendations for enhancing the usability and understandability of process mining in healthcare," Artif. Intell. Med., vol. 109, no. July, 2020, doi: 10.1016/j.artmed.2020.101962.

[16] C. V. Valderrama, E. Santibanez-González, B. Pimentel, A. Candia-Véjar, and L. Canales-Bustos, "Designing an environmental supply chain network in the mining industry to reduce carbon emissions," J. Clean. Prod., vol. 254, 2020, doi: 10.1016/j.jclepro.2019.119688.

[17] S. Kosai, U. Takata, and E. Yamasue, "Natural resource use of a traction lithium-ion battery production based on land disturbances through mining activities," J. Clean. Prod., vol. 280, p. 124871, 2021, doi: 10.1016/j.jclepro.2020.124871.

[18] H. Estiri et al., "Transitive Sequencing Medical Records for Mining Predictive and Interpretable Temporal Representations," Patterns, vol. 1, no. 4, p. 100051, 2020, doi: 10.1016/j.patter.2020.100051. 
[19] C. Ricciardi et al., "Application of data mining in a cohort of Italian subjects undergoing myocardial perfusion imaging at an academic medical center," Comput. Methods Programs Biomed., vol. 189, p. 105343, 2020, doi: 10.1016/j.cmpb.2020.105343.

[20] G. Cho, H.-M. Park, W.-M. Jung, W.-S. Cha, D. Lee, and Y. Chae, "Identification of candidate medicinal herbs for skincare via data mining of the classic Donguibogam text on Korean medicine," Integr. Med. Res., vol. 9, no. 4, p. 100436, 2020, doi: 10.1016/j.imr.2020.100436.

[21] A. Pickens and S. Sengupta, "Benchmarking Studies Aimed at Clustering and Classification Tasks Using K-Means , Fuzzy C-Means and Evolutionary Neural Networks," Mach. Learn. Knowl. Extr., no. 3, pp. 695-719, 2021.

[22] R. Khamisy-farah et al., "Big Data for Biomedical Education with a Focus on the COVID-19 Era : An Integrative Review of the Literature," Int. J. Environ. Res. Public Heal., no. Viii, pp. 1-16, 2021.

[23] A. P. Sousa et al., "Using data mining to assist in predicting reproductive outcomes following varicocele embolization,” J. Clin. Med., vol. 10, no. 16, 2021, doi: 10.3390/jcm10163503.

[24] G. Karakatsoulis and K. Skouri, "Optimal reorder level and lot size decisions for an inventory system with defective items," Appl. Math. Model., vol. 92, pp. 651-668, 2021, doi: 10.1016/j.apm.2020.11.025.

[25] F. Tepolt, K. Montag Schafer, and J. Budd, "Standardization of medication inventory in an urban family medicine clinic," J. Am. Pharm. Assoc., vol. 61, no. 4, pp. e242-e248, 2021, doi: 10.1016/j.japh.2021.03.001.

[26] J. B. Raja and S. C. Pandian, "PSO-FCM based data mining model to predict diabetic disease," Comput. Methods Programs Biomed., vol. 196, 2020, doi: 10.1016/j.cmpb.2020.105659.

[27] H. Wang, X. Tan, Z. Huang, B. Pan, and J. Tian, "Mining incomplete clinical data for the early assessment of Kawasaki disease based on feature clustering and convolutional neural networks," Artif. Intell. Med., vol. 105, no. August 2019, p. 101859, 2020, doi: 10.1016/j.artmed.2020.101859. 